\title{
Large Intestine Infarction due to Mucormycosis Complicated with Acute Myeloid Leukemia. Case Report
}

\author{
Motoharu Shibusawa $^{1, *}$, Hiroko Hidai ${ }^{1}$, Sayuri Motomura ${ }^{1}$, Yuuji Itou ${ }^{2}$, Hisashi Tsutsumi ${ }^{1}$ \\ ${ }^{1}$ Department of Hematology Medicine, Tokyo Metropolitan Health and Medical Treatment Corporation, Tama-Hokubu Medical Center \\ ${ }^{2}$ Department of Pathology, Tokyo Metropolitan Health and Medical Treatment Corporation, Tama-Hokubu Medical Center \\ *Corresponding author: m_sibusawa@hotmail.com
}

Received June 19, 2014; Revised June 24, 2014; Accepted July 07, 2014

\begin{abstract}
Mucormycosis is known to be fatal, and the diagnosis is difficult to be made. Gastrointestinal mucormycosis is rarely complicated with gastrointestinal infarction. We report a rare case of mucormycosis complicated with large intestine infarction. An 82-year-old man was admitted to our hospital, because of blastosis. A diagnosis of acute myeloid leukemia prior myelodysplastic syndrome was made. On the twentieth day of admission, bleeding developed in the airway secondary to thrombocytopenia and disseminated intravascular coagulation. He died due to respiratory failure and autopsy was carried out. The novel finding of the autopsy was large intestine infarction due to mucormycosis, although the clinical course did not show features suggesting gastrointestinal mucormycosis. A diagnosis of mucormycosis was made by autopsy. In the patients with risk factors including hematologic malignancies, we should pay attention to gastrointestinal mucormycosis.
\end{abstract}

Keywords: gastrointestinal mucormycosis, large intestine infarction, acute myeloid leukemia

Cite This Article: Motoharu Shibusawa, Hiroko Hidai, Sayuri Motomura, Yuuji Itou, and Hisashi Tsutsumi, "Large Intestine Infarction due to Mucormycosis Complicated with Acute Myeloid Leukemia. Case Report." American Journal of Infectious Diseases and Microbiology, vol. 2, no. 3 (2014): 51-54. doi: 10.12691/ajidm-2-3-3.

\section{Introduction}

Mucormycosis is known to be fatal, and the diagnosis is difficult to be made. Gastrointestinal mucormycosis may be complicated with gastrointestinal bleeding and perforation, and rarely gastrointestinal infarction. We report a rare case of mucormycosis complicated with large intestine infarction.

\section{Case Presentation}

An 82-year-old man was admitted to our hospital because of blastosis. Ten days before admission, the patient visited another hospital with fatigue, and was treated for anemia (hemoglobin $2.5 \mathrm{~g} / \mathrm{dl}$ ), thrombocytopenia (platelet count $1.5 \times 10^{4} / \mu \mathrm{l}$ ) with blood transfusion (total red cells concentrates 10 units, platelet concentrate 40 units). He had a history of gastrectomy for gastric cancer (65-year-old), hormonal therapy for prostate cancer (73year-old) and endoscopic mucosal resection for colon polyp (73-year-old). His clinical course is shown in Figure 1. At the admission, physical examination revealed Glascow Coma Scale (GCS) E4V5M6, Eastern Cooperative Oncology Group (ECOG) performance status 4, body temperature $39.0^{\circ} \mathrm{C}$, blood pressure $134 / 82 \mathrm{mmHg}$, pulse rate 123 beats per minutes and oxygen saturation $96 \%$ with oxygen 51 per minute, No palpable lymph nodes were observed. Chest auscultation revealed coarse crackles and no murmur. Abdomen was soft, without distention, rebound tenderness, guarding and palpable hepatosplenomegaly. Results of blood examination revealed leukocytosis, blastosis, anemia, thrombocytopenia, abnormality of coagulation and fiblynosis factor indicating disseminated intravascular coagulation (DIC), high serum lactate dehydrogenase, high serum C-reactive protein, and high serum ferritin (Table 1). Chest and abdominal computed tomography revealed bilateral shadows in the lung, pleural effusions and absence of lymphadenopathy, hepatosplenomegaly and abnormal findings with gastrointestinal tract, making a diagnosis of pneumonia. Antibiotic therapy with tazobactam/piperacillin (TAZ/PIPC) was initiated. Bone marrow examination revealed hypercelluar marrow, blasts accounting for $70 \%$, and multilineage dysplasia. A part of blasts was positive for myeloperoxidase, specific and non-specific esterase, and differentiating into monocyte (Figure 2). The blasts were shown to be positive for CD34, CD56, HLA DR, CD7 and CD33 in flow cytometry. A diagnosis of acute myeloid leukemia prior myelodysplastic syndrome was made. Anemia and thrombocytopenia was treated with blood transfusion. High grade fever(over than $38^{\circ} \mathrm{C}$ ) was treated with administration of hydrocortisone $100 \mathrm{mg}$ for antipyresis. On the second day, paroxysmal supraventricular tachycardia appeared and disappeared spontaneously, followed by continuous atrial fibrillation. On the sixth day, micafungin therapy was initiated. On the ninth day, PIPC/TAZ was changed to meropenem. On the thirteenth day, the pneumonia improved, chemotherapy (cytosine arabinoside $10 \mathrm{mg} / \mathrm{m}^{2}$ per 12 hour day1 to 12 , aclarubicin 
$7 \mathrm{mg} / \mathrm{m}^{2} /$ day day1 to 4) was initiated. On the fourteenth day, his consciousness level decreased to GCS E2V3M5. Brain magnetic resonance imaging (diffusion weighted image) revealed high intensity signals in the right basal nuclei, bilateral frontal lobe and left cerebral hemisphere, making a diagnosis of cerebral infarction. A cause of the cerebral infarction presumed atrial fibrillation or hypercoagulation secondary to DIC. The chemotherapy was discontinued. On the twentieth day, bleeding secondary to thrombocytopenia and disseminated intravascular coagulation developed in the airway. He died due to respiratory failure and autopsy was carried out. The novel autopsy findings were as follows: large intestine infarction appeared as mass of transverse colon. A diagnosis of large intestine infarction due to mucormycosis was made by pathological findings (Figure 3). microscopic invasions of leukemic cells in the lung, liver, kidney, gastrointestine, dura mater and para aorta lymphnode. Bleeding was observed in the larynx, trachea, esophagus, mucosa of intestine and renal pelvis. Bronchopneumonia with bleeding and organization was revealed in the lung. Lacunar cerebral infarctions in the bilateral basal nuclei and scattered obsolete cerebral infarction was noted.

Table 1. Laboratory data on admission

\begin{tabular}{|c|c|c|c|c|c|c|c|c|}
\hline WBC & 13700 & $/ \mu \mathrm{l}$ & TP & 5.5 & $\mathrm{~g} / \mathrm{dl}$ & blood sugar & 120 & $\mathrm{mg} / \mathrm{dl}$ \\
\hline RBC & 2.69 & $\times 10^{6} / \mu \mathrm{l}$ & Alb & 2.3 & $\mathrm{~g} / \mathrm{dl}$ & HbA1c (NGSP) & 6.3 & $\%$ \\
\hline $\mathrm{Hb}$ & 8.6 & $\mathrm{~g} / \mathrm{dl}$ & Tbil & 0.6 & $\mathrm{mg} / \mathrm{dl}$ & ferritin & 3168 & $\overline{\mathrm{ng} / \mathrm{ml}}$ \\
\hline $\mathrm{Ht}$ & 25.0 & $\%$ & Dbil & 0.4 & $\mathrm{mg} / \mathrm{dl}$ & candida antigen & negative & \\
\hline Plt & 1.6 & $\times 10^{4} / \mu \mathrm{l}$ & AST & 102 & IU/l & aspergillus antigen & negative & \\
\hline PTINR & 1.54 & & ALT & 63 & $\mathrm{IU} / \mathrm{l}$ & $\beta$-D-glucan & 8.5 & $\overline{\mathrm{pg} / \mathrm{ml}}$ \\
\hline aPTT & 44.9 & sec & LDH & 1625 & $\mathrm{IU} / \mathrm{l}$ & & & \\
\hline fibrinogen & 483 & $\mathrm{mg} / \mathrm{dl}$ & ALP & 228 & $\mathrm{IU} / \mathrm{l}$ & & & \\
\hline ATIII & 55 & $\%$ & LAP & 62 & $\mathrm{IU} / \mathrm{l}$ & & & \\
\hline \multirow[t]{2}{*}{ Ddimer } & 20.2 & $\mu \mathrm{g} / \mathrm{ml}$ & $\gamma \mathrm{GTP}$ & 50 & $\mathrm{IU} / \mathrm{l}$ & & & \\
\hline & & & ChE & 72 & $\mathrm{IU} / \mathrm{l}$ & & & \\
\hline Peripheral blood smear & & & BUN & 26.1 & $\mathrm{mg} / \mathrm{dl}$ & & & \\
\hline Blast & 75.0 & $\%$ & $\mathrm{Cr}$ & 0.72 & $\mathrm{mg} / \mathrm{dl}$ & & & \\
\hline Myelo & 0.5 & $\%$ & UA & 3.3 & $\mathrm{mg} / \mathrm{dl}$ & & & \\
\hline Neu & 14.5 & $\%$ & $\mathrm{Na}$ & 134 & $\mathrm{mEq} / \mathrm{l}$ & & & \\
\hline Lym & 4.0 & $\%$ & $\mathrm{Cl}$ & 104 & $\overline{\mathrm{mEq} / \mathrm{l}}$ & & & \\
\hline Mon & 5.5 & $\%$ & $\mathrm{~K}$ & 4.4 & $\mathrm{mEq} / \mathrm{l}$ & & & \\
\hline Eos & 0.5 & $\%$ & $\mathrm{Ca}$ & 7.4 & $\mathrm{mg} / \mathrm{dl}$ & & & \\
\hline Erythroblast & 2.0 & $\%$ & CRP & 17.45 & $\mathrm{mg} / \mathrm{dl}$ & & & \\
\hline
\end{tabular}

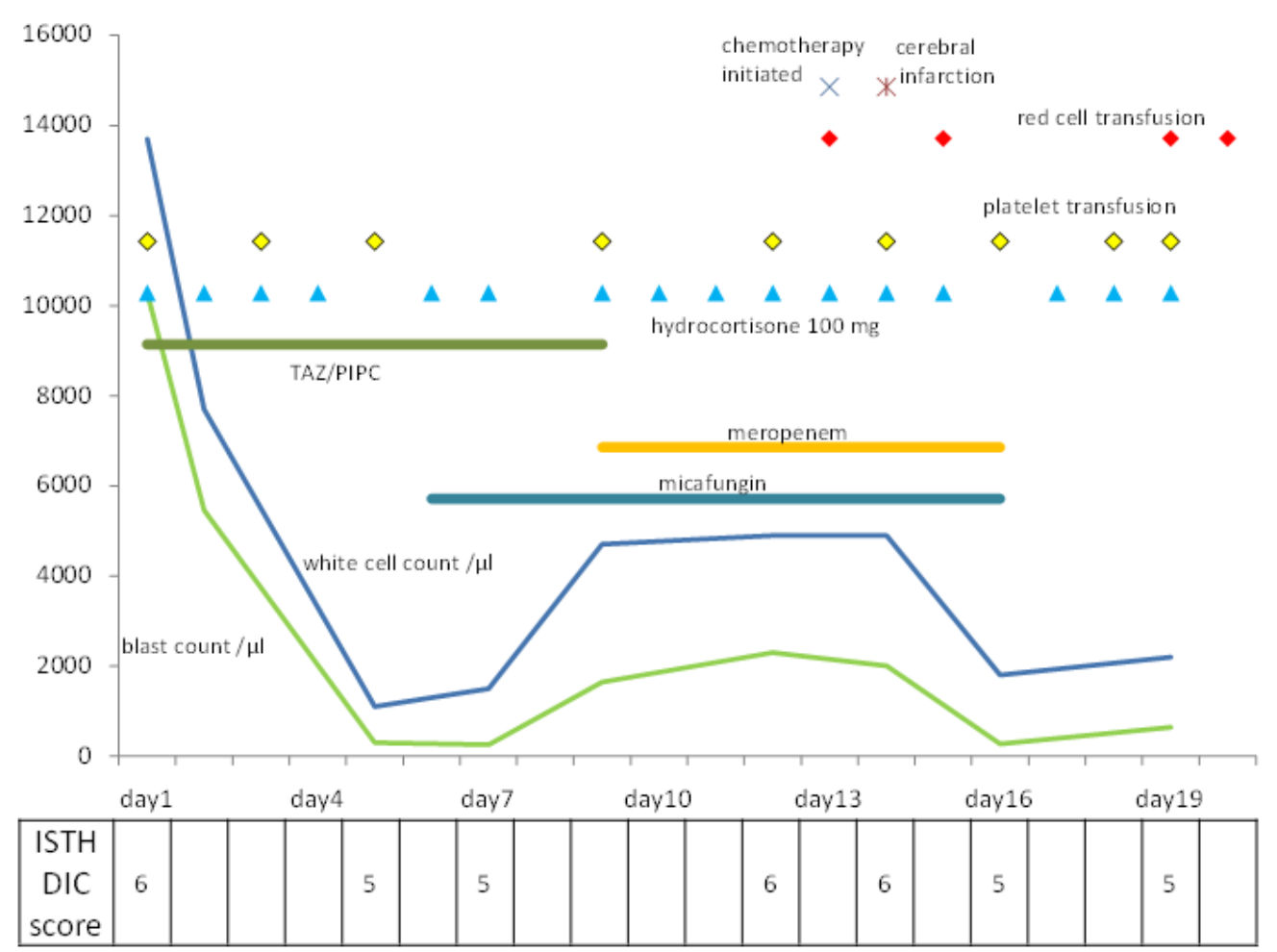

Figure 1. clinical course after admission. ISTH DIC score: Score the test results: Platelet count $\left(>100 \times 10^{9} / \mathrm{l}=0,<100 \times 10^{9} / \mathrm{l}=1,<50 \times 10^{9} / \mathrm{l}=2\right)$, Elevated fibrin marker (e.g. D-dimer, fibrin degradation products) (no increase $=0$, moderate increase $=2$, strong increase $=3$ ), Prolonged PT $(<3$ sec $=$ $0,>3$ but $<6 \mathrm{sec}=1,>6 \mathrm{sec}=2$ ), Fibrinogen level $(>1 \mathrm{~g} / \mathrm{l}=0,<1 \mathrm{~g} / \mathrm{l}=1$ ), The International Society for Thrombosis and Haemostasis(ISTH), reference 


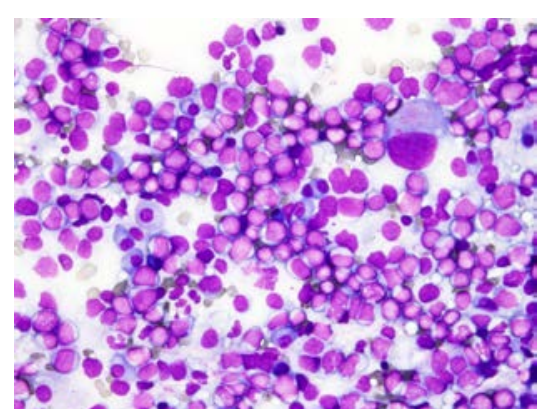

(a)

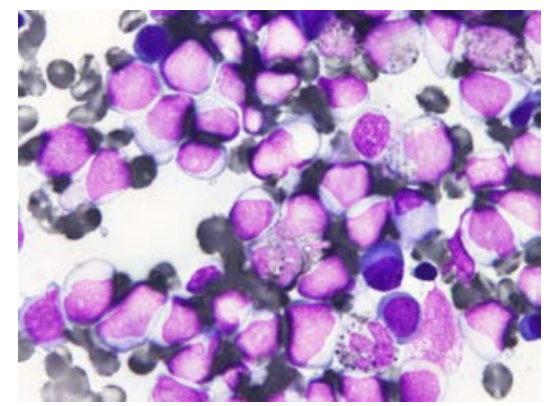

(c)

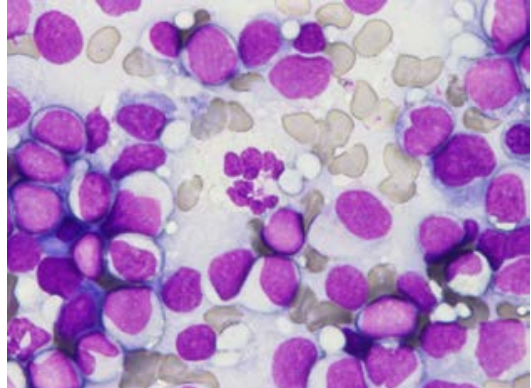

(b)

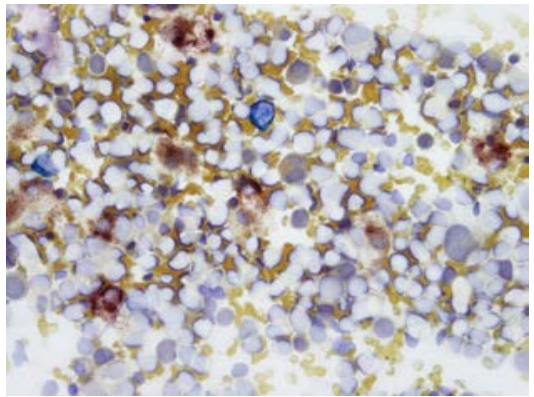

(d)

Figure 2. Microscopic findings of bone marrow liquid smear: (a) hypercelluar marrow ( $\times 400$, May-Giemsa stain); (b) multilineage dysplasia was noted. Blasts (accounting for $70 \%)$ were differentiating into monocyte. $(\times 1000$, May-Giemsa stain); (c) A part of blasts was positive for myeloperoxidase $(\times 1000$, myeloperoxidase stain); (d) A part of blasts was positive for specific and non-specific esterase $(\times 400$, specific and non-specific esterase stain)

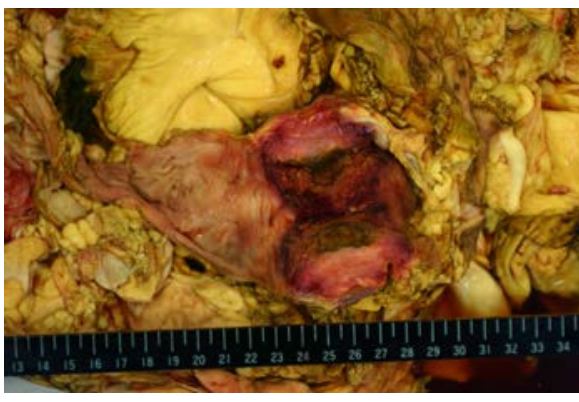

(a)

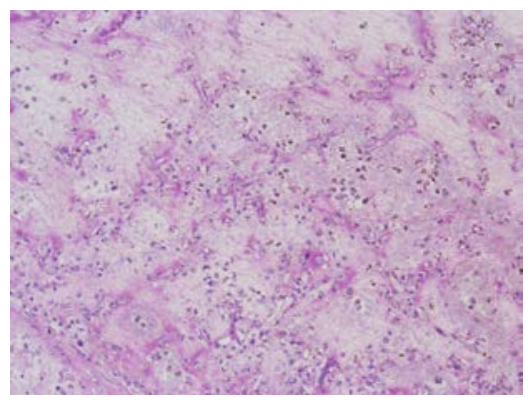

(c)

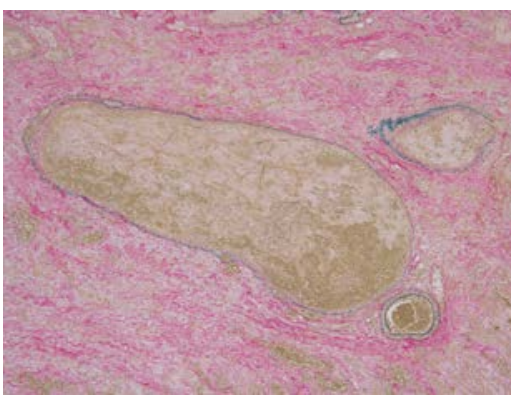

(b)

Figure 3. Pathological findings of large intestine infarction due to mucormycosis: (a) Macroscopic photograph: large intestine hemorrhagic infarction appeared as mass (size $60 \times 45 \times 40 \mathrm{~mm}$ ) of transverse colon: (b)-(c) Microscopic photograph of the large intestine infarction: multiple mycotic embolisms of small vessels were noted. (b) Mycotic embolism of small vessels in submucosa (Victoria blue haematoxylin-eosin stain, $\times 40$ ); (c) Mycotic embolism of small vessels in submucosa (Periodic acid-Schiff stain (PAS), $\times 200)$ Filamentousfungi (7-14 $\mu m)$ were noted, hyphae were PASpositive,varying in width, non-septate, random angled branching

\section{Discussion}

Mucormycosis is an important pathogen, and increasing in patients with hematological malignancies and hematopoietic cell transplantation for past decade [2]. Risk factors of mucormycosis are as follows; hematological malignancies, hematopoietic stem cell transplantation, solid organ malignancies, solid organ transplantation, diabetes mellitus, ketoacidosis, corticosteroid, rheumatic disease, iron overload, chelation therapy with deferoxamine, pronged use of voriconazole and acquired immunodeficiency disease. Hematological malignancies (HM) are one of the risk factors. Among HM, acute myeloid leukemia (AML) is the highest risk. The incidence of mucormycosis complicated with AML is ranging from 1 to $8 \%$ [1]. In our case, the risk factors were acute myeloid leukemia and, possible iron overload due to blood transfusion (total red cells concentrates 18 units) and corticosteroid (frequent administration of hydrocortisone $100 \mathrm{mg}$ for antipyresis). 
Kurosawa.M et al reported 2,821 patients with hematological malignancies, including 597 who had undergone hematopoietic cell transplantation. Invasive fungus infections were diagnosed in 38 (1.3 \%) patients. Mucormycosis were diagnosed in 6 patients, including 3 who were diagnosed by autopsy [2]. Mucormycosis is rare and difficult to make the diagnosis in antemortem. In our case, the clinical course did not show features suggesting gastrointestinal mucormycosis, and the diagnosis of mucormycosis was made by autopsy.

Mucormycosis is roughly classified as rhinocerebral, pulmonary, cutaneous, gastrointestinal, disseminated, and uncommon forms [1]. Roden MM et al reported infection sites of mucormycosis in patients with malignancy. Respiratory accounts for the majority (60\%), gastrointestinal accounts for only $3 \%$ [3]. Thus, in patients with malignancy, gastrointestinal mucormycosis is rare.
Gastrointestinal mucormycosis is acquired by ingestion of pathogens in foods such as fermented milk and dried bread products. Consumption of fermented porridges, alcoholic drinks derived from corn, use of sporecontaminated herbal and homeopathic remedies are linked with gastrointestinal mucormycosis. The mortality rate of gastrointestinal mucormycosis is as high as $85 \%$. Only $25 \%$ of gastrointestinal mucormycosis are diagnosed antemortem. In neutropenic patients, gastrointestinal mucormycosis usually presents as a masslike appendiceal or ileal lesion. Gastrointestinal mucormycosis affects the stomach commonly, followed by the colon and ileum. Diagnosis of gastrointestinal mucormycosis is usually delayed, because of nonspecific presentation. Mucormycosis can invade colon walls and blood vessels. Common causes of death are colon perforation, peritonitis and massive gastrointestinal hemorrhage [1].

Table 2. Case reports of gastrointestinal mucormycosis

\begin{tabular}{|c|c|c|c|c|c|c|c|}
\hline case & age/sex & predisposing conditions & diagnosis & infection site & presentation & outcome & reference \\
\hline 1 & $53 / \mathrm{F}$ & bacterial infection & laparotomy & intestine, colon & abdominal distension & died & 4 \\
\hline 2 & $59 / \mathrm{M}$ & alcohol, bacterial infection & laparotomy & intestine & acute abdomen & survived & 5 \\
\hline 3 & $70 / \mathrm{F}$ & septic shock & colonoscope & colon & gasrtointestinal bleeding & died & 6 \\
\hline 4 & $59 / \mathrm{M}$ & septic shock & colonoscope & colon & gasrtointestinal bleeding & survived & 7 \\
\hline 5 & 69/M & pneumonia & laparotomy & colon & acute abdomen & died & 8 \\
\hline
\end{tabular}

Case reports of gastrointestinal mucormycosis are shown in Table 2. All cases presented with non-specific abdominal symptom. Case 1-4 were complicated with gastrointestinal bleeding or perforation, and only case 5 with gastrointestinal infarction. In our case, large intestine infarction was noted as a rare complication of gastrointestinal mucormycosis. In addition, all cases were affected by gastrointestinal mucormycosis after infection. Our case was also affected by pneumonia. Although, in general, infection is not recognized as the risk factor, infection may be associated with gastrointestinal mucormycosis.

\section{Conclusion}

Gastrointestinal mucormycosis is fatal, and the diagnosis is difficult to be made. In the patients with risk factors including $\mathrm{HM}$, we should pay attention to gastrointestinal mucormycosis.

\section{Acknowledgements}

We appreciate the support by Dr. Nobuhiko Aoki.

\section{Competing Interests}

The author have no competing interests.

\section{List of Abbreviations}

Eastern Cooperative Oncology Group: ECOG; glascow coma scale: GCS; tazobactam/piperacillin: TAZ/PIPC; disseminated intravascular coagulation: DIC; hematological malignancies: HM; acute myeloid leukemia:
AML; The International Society for Thrombosis and Haemostasis: ISTH; Periodic acid-Schiff stain: PAS.

\section{References}

[1] Petrikkos G, Skiada A, Lortholary O, Roilides E, Walsh TJ, Kontoyiannis DP.Epidemiology and clinical manifestations of mucormycosis.Clin Infect Dis. 2012 Feb.

[2] Roden MM1, Zaoutis TE, Buchanan WL, Knudsen TA, Sarkisova TA, Schaufele RL, Sein M, Sein T, Chiou CC, Chu JH, Kontoyiannis DP, Walsh TJ.Epidemiology and outcome of zygomycosis: a review of 929 reported cases.Clin Infect Dis. 2005 Sep.

[3] Kurosawa M1, Yonezumi M, Hashino S, Tanaka J, Nishio M, Kaneda M, Ota S, Koda K, Suzuki N, Yoshida M, Hirayama Y, Takimoto R, Torimoto Y, Mori A, Takahashi T, lizuka S, Ishida T, Kobayashi R, Oda T, Sakai H, Yamamoto S, Takahashi F, Fukuhara T.Epidemiology and treatment outcome of invasive fungal infections in patients with hematological malignancies.Int $\mathrm{J}$ Hematol. 2012 Dec.

[4] Roussy JF1, Allard C, St-Germain G, Pépin J.Gastrointestinal Mucormycosis following a Streptococcus pyogenes Toxic Shock Syndrome in a Previously Healthy Patient: A Case Report.Case Rep Infect Dis.2012 Jul.

[5] Martinello M, Nelson A, Bignold L, Shaw D."We are what we eat!" Invasive intestinal mucormycosis: A case report and review of the literature.Med Mycol Case Rep. 2012 Aug.

[6] Anand J, Ghazala K, Chong VH.Massive lower gastrointestinal bleeding secondary to colonic mucormycosis.Med J Malaysia. 2011 Aug.

[7] Ramaswami A, Pisharam JK, Aung H, Ghazala K, Maboud K, Chong VH, Tan J.Co-incidental Plasmodium Knowlesi and Mucormycosis infections presenting with acute kidney injury and lower gastrointestinal bleeding. Am J Case Rep. 2013 Apr.

[8] Choi HL1, Shin YM, Lee KM, Choe KH, Jeon HJ, Sung RH, Shin KS, Shin YD, Yun HY, Song YJ, Choi JW, Ryu DH.Bowel infarction due to intestinal mucormycosis in an immunocompetent patient.J Korean Surg Soc. 2012 Nov.

[9] Levi M1, Toh CH, Thachil J, Watson HG.Guidelines for the diagnosis and management of disseminated intravascular coagulation. British Committee for Standards in Haematology.Br J Haematol. 2009 Apr. 